\title{
Concepções e Práticas da Equipe Multiprofissional Sobre o Aborto Legal em Hospital Materno- Infantil de Fortaleza-Ce
}

\author{
Rosane Vasconcelos Castelo Branco Mourão
}

Mestre em Planejamento em Políticas Publicas - UECE

\section{Maria do Socorro Ferreira Osterne}

Doutora em Serviço Social pela Universidade Federal de Pernambuco - UFPE

Professora do Programa de Pós-Graduação em Políticas Públicas (PPGPP) da UECE

\section{Resumo}

O presente artigo tem o objetivo de investigar como pensam e agem os profissionais de saúde que compõem a equipe multiprofissional responsável em atender mulheres em situação de violência sexual que desejam realizar o aborto legal no Hospital Distrital Gonzaga Mota Messejana. Para isso, foi realizada pesquisa bibliográfica além de pesquisa de campo, por meio da observação participante, de registros em diário de campo, e da aplicação de entrevista semiestruturada e de questionário. A pesquisa mostra que os profissionais não estão devidamente capacitados para atuarem neste tipo de serviço, poucos conhecem as normas vigentes sobre o assunto. No entanto, procuram agir de forma ética, conforme a dinâmica e as determinações da unidade hospitalar definidas pelas coordenações dos setores, e atendem as usuárias que desejam realizar o aborto legal apesar de serem contra o procedimento. Esta pesquisa proporcionou discutir as dificuldades e desafios enfrentados pelos profissionais no sentido de garantirem um melhor atendimento às mulheres que vivenciam este tipo de violência, bem como poderá contribuir para visualizar questões que precisam ser revistas para que as usuárias deste serviço tenham seus direitos devidamente garantidos.

Palavras-chave: Violência sexual. Saúde da mulher. Aborto legal. Práticas profissionais. 


\section{Abstract}

This article aims to investigate how they think and act healthcare professionals that make up the multidisciplinary team responsible to meet women in sexual violence situations who wish to perform legal abortions in the District Hospital Gonzaga Mota Messejana. For this literature search was performed in addition to field research, through participant observation, records in field diary, and the application of semi-structured interview and questionnaire. Research shows that professionals are not properly trained to work in this type of service, few know the rules in force on the subject. However, they try to act ethically, as the dynamics and determinations of the hospital unit defined by the coordination of the sectors, and meet the users who wish to perform legal abortion despite being against the procedure. This research provided discuss the difficulties and challenges faced by professionals in order to ensure better care for women who experience this kind of violence, and may contribute to view issues that need to be reviewed so that the users of this service have their duly guaranteed rights.

Key words: sexual violence. Women's health. Abortion legal. Professional Practices. 


\section{Introdução}

Questões referentes ao aborto, mais precisamente ao aborto legal, vem ganhando notoriedade no momento atual devido a alguns fatores marcantes e significativos. A atuação dos movimentos feministas, que há alguns anos reivindica o enfrentamento do aborto como um problema de saúde pública e também de direitos humanos, assim como as diretrizes normativas do Ministério da Saúde que foram implementadas com o intuito de definir e organizar como deve ser a atenção direcionada a este assunto pelos profissionais e pela gestão das unidades de saúde, são exemplos de como o assunto está definitivamente em pauta na atualidade.

Além disso, a mídia também tem contribuído significativamente pondo em destaque situações de violência sexual contra as mulheres, fazendo aparecer seus desdobramentos, relatando quase que diariamente reportagens e notícias sobre casos vivenciados por elas, os quais, muitas vezes, resultam em morte.

Nestas situações, a sociedade, de uma maneira geral, é tomada pela indignação e pela revolta. Amplia suas discussões incitadas pelas redes sociais, independente de contexto, classe ou idade. Dessa forma, começa-se a questionar certos paradigmas, tais como o que é estupro de fato, e até que ponto as vítimas são revitimizadas pela própria sociedade representada pelos grupos mais conservadores e reacionários. Também se inicia uma discussão sobre a necessidade de mudanças da legislação referente ao problema, mas também sobre a forma como os casos são expostos pela grande mídia, com tendência à banalização do trágico.

Em relação ao aborto legal, primeiramente deve-se saber que abortamento refere-se a uma intervenção que resulta em uma mulher expelir o que se chama de aborto. Isto é, o material com peso menor que 500 gramas resultado da gravidez, que se não fosse expelido resultaria na formação de um feto. $\mathrm{O}$ abortamento pode ser ocasionado por diversas formas, podendo ser espontâneo ou não. Já o aborto legal, trata somente de casos previstos por lei, ou seja, pode ser realizado pela intervenção de um médico, sob o acompanhamento de uma equipe multiprofissional, sem a criminalização destes e da mulher que opta em realizar o procedimento.

No Brasil, é previsto pelo Código Penal de 1940 duas possibilidades de aborto legal, e mais recentemente, através de resolução promulgada pelo Supremo Tribunal Federal, uma terceira possibilidade de ser realizado abortamento sem a mulher, tampouco o médico precisarem responder criminalmente pelo ato. Este último caso se refere a bebês anencéfalos, enquanto as outras duas formas anteriores se referem ao que se chama de aborto necessário, quando não há outro meio de salvar a vida da gestante, e aborto no caso de gravidez resultante de estupro.

O interesse em realizar esta pesquisa, que se tem como pergunta de partida: "De que forma a postura dos profissionais de saúde frente à questão do aborto legal pode influenciar no atendimento às mulheres vítimas de violência sexual no Hospital Distrital Gonzaga 
Mota Messejana?", deve-se ao fato da literatura revelar que a maioria dos hospitais que se propõe a atender estas mulheres, não se mostram adequados para tal, principalmente no que se refere ao atendimento realizado pelas equipes. $O$ campo escolhido constitui-se a única unidade de saúde na cidade de Fortaleza que realiza o procedimento do aborto legal nos casos de violência sexual.

Alguns estudos e pesquisas sobre este assunto indicam, conforme relata Lemos e Russo (2014, p. 302), uma realidade na qual "a assistência a mulheres que buscam serviços de saúde no caso de aborto provocado é desumanizada, discriminatória e estigmatizada". Tal indicação aguçou a curiosidade e o interesse de investigar a atuação da equipe multiprofissional que atende neste Hospital, bem como de que maneira estas mulheres são atendidas e assistidas.

Autores como Faúndes (2004), Andalaft Neto (2004), Soares (2003), Dip (2013), Lemos e Russo (2014) são unânimes em afirmar, após pesquisa, que as mulheres que buscam os serviços de saúde para a realização do aborto legal são muitas vezes, vitimas de preconceito e discriminação por parte dos profissionais que as atendem. Lemos e Russo (2014, p.302) afirmam que

$\mathrm{O}$ atendimento tende a ser punitivo e discriminador, gerando nas mulheres sentimentos de insegurança, angústia, culpa e humilhação, num flagrante desrespeito às diretrizes que preconizam o direito de todos a uma assistência humanizada e de qualidade (LEMOS E RUSSO, 2014, p.302).

Prováveis explicações para isso residem na tendência dos profissionais se guiarem por critérios de ordem moral e religiosa em sua prática assistencial, enfim, por questões de ordem pessoal, e não pelas conquistas normativas inerentes à situação. A consequência disso é a usuária ser prejudicada, e mais ainda, ser novamente violentada pela via dos preconceitos predominantes na dinâmica institucional.

Desta forma, tem-se como objetivo principal neste estudo, investigar como pensam e agem os profissionais de saúde frente à questão do aborto legal, e quais as implicações de suas posturas no que se refere ao atendimento às mulheres vítimas de violência sexual no Hospital Distrital Gonzaga Mota Messejana. Para tal, esta pesquisa, que é de natureza qualitativa, optou pelo método da observação participante, tendo como campo o Hospital acima citado. Como técnica de coleta dos dados utilizou-se da aplicação de entrevistas semiestruturadas e de questionários, além do diário de campo.

A pesquisa contou com a participação de quatro sujeitos entrevistados, sendo um médico, uma enfermeira, uma psicóloga e uma assistente social, e mais 21 que responderam ao questionário, sendo cinco médicos, quatro enfermeiros, seis psicólogos e seis assistentes sociais. Todos compõem a equipe multiprofissional que atende e acompanha a 
mulher que chega ao campo após ter vivenciado situação de violência sexual, e que muitas vezes opta pelo aborto legal.

O desenvolvimento desta pesquisa proporcionou uma maior visibilidade às dificuldades e desafios enfrentados pelos profissionais no sentido de garantirem um melhor e mais adequado atendimento às mulheres que vivenciam situação de violência sexual, e que em determinadas vezes, resulta numa gravidez indesejada e não planejada, que gera o desejo em realizar o aborto legal.

\section{A atuação da equipe multiprofissional nos casos de violência sexual e de aborto legal: como ela se confi- gura e se apresenta}

Sobre a atuação dos profissionais que compõem a equipe que atende as mulheres vítimas de violência sexual e aquelas que ensejam realizar o aborto legal, vários são os autores que dialogam sobre a necessidade de se ter na unidade de saúde profissionais capacitados e qualificados para tal.

Desta forma, inúmeras são as normatizações lançadas pelo Ministério de Saúde para regulamentar de que forma deve ser a prática dos profissionais em relação ao serviço de atendimento às mulheres vítimas de violência sexual que ensejam realizar o aborto legal.

Porém, estudos e pesquisas sobre $o$ assunto mostram que a equipe multiprofissional responsável em atender e acompanhar a mulher somente irá seguir tais princípios se ela estiver devidamente capacitada, sensibilizada e treinada para tal. Somente assim, essa mulher será devidamente acolhida, orientada e atendida, e seus direitos devidamente garantidos.

Quanto a isso, Loureiro e Vieira (2004, p.681) afirmam que "maior parte dos serviços de saúde não está preparada para atender as mulheres vítimas de violência e, particularmente, os casos de estupro". Medeiros et al afirmam que:

uma das dificuldades para a garantia do direito à saúde e para a adequada atuação profissional é o desconhecimento por parte dos profissionais e da população em geral acerca da legislação brasileira e dos princípios estabelecidos pelo Sistema Único de Saúde (SUS). (MEDEIROS ET AL, 2012, p.17).

Já Loureiro e Vieira (2004, p.687) afirmam que "embora tenham conhecimento razoável sobre as leis do aborto, a maioria dos médicos demonstrou não conhecer aspectos 
práticos importantes de sua aplicação", uma vez que, habitualmente o BO é exigido por eles mesmo não sendo obrigatório.

Desta forma, é comum observar que é corriqueira a recusa dos profissionais de saúde em realizar o aborto, uma vez que quando não se tem o conhecimento técnico sobre o assunto, há o temor e o receio em fazer algo ilegal, além dos julgamentos, dos tabus e da estigmatização que acompanham o tema referente a aborto. Soma-se a isso o fato de, segundo D'Oliveira e Schraiber

Os profissionais de saúde tendem a compreender a violência doméstica e sexual como problemática que não diz respeito à assistência médica, mas sim à esfera da segurança pública e à justiça, devendo, pois, ser reconhecida e enfrentada nas delegacias ou no sistema judiciário (D'OLIVEIRA E SCHRAIBER, 1999, p.5).

Conforme Farias e Cavalcanti (2012), ainda existe o problema do uso inadequado do direito à objeção de consciência' por parte dos profissionais de saúde. E uma vez sendo feito uso de tal direito de maneira irregular, o direito ao atendimento à mulher que quer realizar o aborto legal é inviabilizado. As autoras constataram também:

(...) a existência de diferentes dificuldades dos profissionais na construção de uma postura capaz de garantir o acesso ao aborto previsto em lei, e a interferência dos princípios éticos e dos valores religiosos como um elemento importante na postura do profissional que desestimula a prática do aborto legal (FARIAS E CAVALCANTI, 2012, p.1755).

1 Conforme artigo 7 do Código de Ética Médica, "o médico deve exercer a profissão com autonomia, não sendo obrigado a prestar serviços profissionais a quem ele não deseje, salvo na ausência de outro médico, em casos de urgência, ou quando sua negativa possa trazer danos irreversíveis ao paciente". E no artigo 9, diz que ele pode "recusar a realização de atos médicos que, embora permitidos por lei, sejam contrários aos ditames de sua consciência". Assim, é garantida ao médico a objeção de consciência e o direito de recusa em realizar o abortamento em casos de gravidez resultante de violência sexual. No entanto, é dever do médico informar à mulher sobre seus direitos e, no caso de objeção de consciência, deve garantir a atenção ao abortamento por outro profissional da instituição ou de outro serviço. Não se pode negar o pronto atendimento à mulher em qualquer caso de abortamento, afastando-se, assim, situações de negligência, omissão ou postergação de conduta que viole a lei, o código de ética profissional e os direitos humanos das mulheres (BRASIL, 2012). 
Sobre essa realidade, Oliveira (1999, p.15) afirma:

\begin{abstract}
Sabe-se que profissionais de saúde sensibilizadas/os e bem treinadas/ os são agentes fundamentais na quebra do "ciclo da violência". Já está passando da hora de o governo compreender a importância que os serviços de saúde podem ter no trato da violência doméstica, pois são os serviços mais procurados pelas mulheres em situação de violência, em especial os prontos socorros.
\end{abstract}

Drezett (2003, p.46) reforça que "profissionais e provedores de saúde deveriam estar adequadamente capacitados para o manejo clínico e psicológico das vítimas de violência sexual". O autor acredita que, somente assim, a mulher que sofreu violência poderá ter o atendimento emergencial e profilático para não vir a contrair doenças ou uma possível gravidez, bem como ter acompanhamento social e psicológico para superar a violência vivenciada. E ressalta ainda:

As sobreviventes da violência sexual esperam mais que a simples aplicação de protocolos de conduta. Esperam receber atenção digna e respeitosa. Cabe aos profissionais de saúde o reconhecimento de seu importante papel no destino dessas mulheres. E o exercício ético e responsável de medidas protetoras de sua saúde e de seus direitos humanos (DREZETT, 2003, p.50).

\title{
2. O serviço de aborto legal no campo da pesquisa e suas peculiaridades
}

O serviço de atendimento a pessoa em situação de violência sexual no Gonzaguinha de Messejana ${ }^{2}$, assim como o de aborto legal, são referências não só no município de Fortaleza, como no estado do Ceará. Isso significa que a unidade é conhecida como tal, e por isso, a rede encaminha os casos diretamente para ali serem atendidos. Configura-se atualmente como o único hospital que possui uma equipe preparada e capacitada para a realização do aborto legal ${ }^{3}$.

2 É a forma como o Hospital Distrital Gonzaga Mota Messejana é conhecido e popularmente chamado.

3 Alguns hospitais da rede municipal de Fortaleza-CE já oferecem o serviço de atendimento a pessoas em 
No que se refere à equipe que atua no Gonzaguinha de Messejana, foi perguntado como eles percebiam a atuação dos profissionais em relação a estarem capacitados para atuarem especificamente no serviço do aborto legal ou não, e a psicóloga logo afirmou: capacitação é dada, nem todos participam, e a enfermeira endossou: não, não estão capacitados. Precisaria ter mais treinamento. A assistente social ressaltou: pra melhorar [o serviço], todo mundo tem que estar capacitado, e elas [capacitações] devem ser sistemáticas.

Foi dada ênfase a esta questão porque inúmeros estudiosos sobre o tema constatam, através de pesquisas, que falta acontecer um preparo melhor dos profissionais para atuarem neste serviço. Farias (2012, p.1759) afirma, em relação a esta realidade, que "há um número significativo de profissionais de saúde que atuam no atendimento às mulheres com demanda por aborto legal e que não participaram de atividades de capacitação". Somente devidamente capacitado e sensibilizado que, segundo Rocha (2015, p.394), seria possivel adquirir:

[...] uma conduta na qual deve abstrair suas convicções morais, culturais, religiosas, bem como outros aspectos que possam influir no atendimento à paciente; ou seja, sua atitude deve ser norteada, acima de tudo, pela imparcialidade (justiça).

Uma vez não capacitados, torna-se comum mulheres buscarem os serviços de saúde já fragilizadas devido à violência vivenciada, e serem vitimas de preconceito e do despreparo dos profissionais que as atendem. Segundo Lemos e Russo (2014, p. 302), "o atendimento tende a ser punitivo e discriminador, gerando, nas mulheres, sentimentos de insegurança, angústia, culpa e humilhação, num flagrante desrespeito às diretrizes que preconizam o direito de todos a uma assistência humanizada e de qualidade".

As autoras reforçam que, "não raro, os profissionais de saúde utilizam seus próprios critérios morais em suas práticas assistenciais, e adotam ações punitivas em seu atendimento às mulheres que praticam o aborto, agindo como verdadeiros juízes". Desta forma, o atendimento se torna desumanizado, discriminatório e estigmatizado, ou seja, totalmente o contrário do que prevê a lei e as normatizações.

Talvez por não haver predominância desta postura isenta de valores morais e pessoais por grande parte dos profissionais que atuam no Gonzaguinha de Messejana, que a enfermeira afirmou:

situação de violência sexual, enquanto que, no caso da realização do aborto legal, alguns estão se organizando e se capacitando para tal, e até iniciando os primeiros procedimentos, como é o caso da Maternidade Escola Assis Chateaubriand. 
Acho que existe muita gente despreparada. Com certeza, demais! As pessoas não têm preparo. Não é porque não tá tratando mal, tratando com grosseria, que você esteja fazendo um tratamento adequado, não é isso! Tem que ter um treinamento na questão do lidar em si... do lidar com a situação em si de violência, na questão do conversar, da discrição, de pra onde encaminhar, como encaminhar...

Além de uma postura julgadora apresentada por alguns profissionais como cita a enfermeira: aqui dentro da sala eu não vejo preconceito, não vejo um atendimento de forma diferenciada não, [...] só não gosto daquela parte "a paciente do aborto", dos comentários de alguns profissionais...ainda se percebe um comportamento antiético como menciona a assistente social: [...] ela passa pelo acolhimento com a enfermeira, e é encaminhada pela auxiliar de enfermagem que não sabe de nada e quando sabe ela espalha, aí fica todo mundo sabendo, e ela [a usuária] se sente muito, muito constrangida.

Outra situação grave relatada pela psicóloga que ocorre no campo desta pesquisa é a diferenciação escancarada feita por alguns profissionais em relação a determinadas situações, resultando num atendimento diferenciado e desigual:

Quando é violência sexual e ela vem logo de inicio, nas 72 horas, os profissionais se sensibilizam muito, querem o mais rápido possivel tá ajudando, são muito curiosos, querem saber o que está acontecendo, as vezes a ética é passada por cima, as pessoas querem saber, querem que a gente conte o que tá acontecendo, como é que é a história, se é verdade ou não, ficam fofocando entre si, passando a história, as vezes até vão de encontro à ética, ao sofrimento daquela pessoa, ne. Já em relação ao aborto legal, existe medo, existe preconceito, e existe objeção.

O fato que a psicóloga relatou foi percebido por mim durante a observação participante, de que, nos casos de profilaxia, ou seja, em que a violência ocorreu há menos de três dias, a usuária tende a ser melhor acolhida e os profissionais mais sensibilizados com o ocorrido. Já quando ela chega ao serviço relatando uma violência que aconteceu em um período maior de tempo, e que se descobriu gestante e tem o interesse no aborto legal, ela muitas vezes é alvo de julgamentos e preconceito, e da própria objeção em atendê-la.

Da mesma forma, foi observado por Soares (2003, p.401) que, na interrupção da gravidez por risco de vida no primeiro trimestre, ela encontrou mais aceitação entre os médicos, enquanto que o mesmo não acontece quando a interrupção é decorrente de estupro. Segundo ela, "o poder médico interdita ou referenda a prática do abortamento, facili- 
tando ou criando impedimentos de acordo com o caso apresentado".

Lemos e Russo (2014, p.302) enfatizam que "o cuidado à mulher que interrompe a gravidez diz respeito à garantia do direito à saúde, que é constitucional”. Desta forma, elas ressaltam o fato que, o profissional de saúde no exercício de sua prática profissional, é antes de tudo um representante do Estado, e seus valores não deveriam, portanto, sobrepor-se à Lei. No entanto, sabemos infelizmente que não é isso que ocorre.

A enfermeira do Gonzaguinha de Messejana afirmou que já se deparou com a recusa de uma residente em não querer aplicar o misoprostol na paciente, mas relevou justificando o fato dela não ser médica ainda, e por ter agido corretamente ao passar o caso a um colega, que deu continuidade: foi bem discreto, e agiu continuando o atendimento, não parou de atender por causa disso.

Já o médico declarou que infelizmente poucos médicos fazem isso [o procedimento do aborto legal], eles alegam questões religiosas, e ressalta que eles se utilizam do prurido religioso, terrível. A psicóloga mencionou ainda o fato de que normalmente os médicos só fazem depois que é feito a primeira introdução do misoprostol [após a aplicação pelo médico entrevistado].

A recusa em realizar o procedimento foi citada pelos profissionais entrevistados como também foi observado por mim, de fato ocorre no campo desta pesquisa, em diversas situações, e por alguns profissionais. O argumento mais utilizado para agirem desta forma é o discurso religioso como foi citado pelo médico. Em relação a isso, Farias e Cavalcanti (2012, p.1761) ressaltam:

\footnotetext{
A presença do discurso religioso, observado na fala de alguns profissionais de saúde, ainda que muitas vezes confundido com o direito à objeção de consciência, demonstra que diante de uma cultura impregnada por uma religião de salvação, algumas normas estabelecidas passam a ser consideradas como violação da vontade divina.
}

Mesmo sabendo que não é competência do profissional o julgamento da informação apresentada pela usuária do serviço, e que, de uma maneira geral, os profissionais entendem que devem manter uma postura neutra e imparcial a respeito da decisão da mulher, não devendo julgá-la por ter optado pelo aborto legal, o fato é que muitas vezes os profissionais agem de forma contrária ao que deveria ser feito (ROCHA et al, 2015; SOARES, 2003).

Apesar de ser referência, e devido a isto, a demanda recebida ser razoável, e por este motivo o serviço estar constantemente sendo revisto na tentativa de ser melhorado, os profissionais entrevistados relataram enfrentarem algumas dificuldades no desempenho de suas funções, sendo algumas delas basicamente de ordem burocrática e de gestão. 
Ao serem indagados sobre as principais dificuldades enfrentadas por eles no cotidiano de suas atuações neste serviço de referência, os profissionais citaram de imediato a questão da estrutura física inadequada para melhor atender as usuárias.

O médico disse: eu acho que elas não deveriam ficar próximo às pacientes que estão parindo, era pra ser, aí a questão é física, eu acho que elas deveriam ficar em outro setor, um setor isolado. Já a enfermeira ressaltou:a gente tem uma equipe preparada, a gente tem o serviço social, o psicólogo, enfermeiros bons, os médicos bons, mas o que falta realmente é a estrutura. Procura a gente tem, paciente a gente tem, mas a estrutura pra atender esse tipo de paciente não existe. A psicóloga acrescentou: nós poderíamos ter um local especifico, deveríamos ter, quer dizer, um local específico para acolhê-la onde todos os profissionais poderiam atuar junto com ela [usuária].

A questão da estrutura física inadequada e o fato de não se ter uma sala especifica para este atendimento foi bastante reforçada por todos. Foi colocado pela enfermeira, psicóloga e assistente social como o principal elemento dificultador do atendimento correto, sigiloso e ético, conforme as falas a seguir:

O que ta precisando é realmente de um espaço pra essas pacientes, e principalmente pras vítimas de violência, a gente tem criança vitima de violência que entra aqui assustada, vê paciente gritando em trabalho de parto, vê tudo, o adulto mesmo, você não tem espaço, daí você não tem como conversar, não tem como abordar, você vai orientar, você vai perguntar, tem que ser tudo muito discreto, como ter discrição? Em uma sala com seis, sete cadeiras? Você fica constrangida e constrange a pessoa, e a pessoa que ta do lado percebe que você ta querendo disfarçar alguma coisa, por que você ta querendo disfarçar? E assim, como aqui é muito procurado, eu acho que deveria investir na questão da estrutura física, até porque não é um atendimento que deve ser misturado, eu acho. "Ah, tem que ser excluido?”. Não, não tem que ser excluido, mas tem que ser diferenciado, diferenciado para melhor, eu vejo dessa forma (enfermeira).

A estrutura física não contempla totalmente o que a norma técnica diz, ne, o numero de profissionais não é suficiente, por exemplo, nós não temos psicologia a noite nem no final de semana, nós não temos médico que faz essa atividade todos os dias e todas as horas como preconiza a norma, ne, fisicamente nós não temos espaço próprio pra atender essa pessoa, ela é atendida dentro de uma sala de parto, quando esta em processo de parto, ela ta junto de outras mulheres parindo (psicóloga).

Pois sim, o hospital, pra ele ser um hospital de referência, ele também tem que ter a referência, qual e a referência do atendimento de violência? 
Qual é a sala de atendimento da violência? Não tem uma referência, entendeu? E esse fator é que eu acho que é o mais critico. Eu acho que é onde toca: como acolher uma familia? Porque as vezes a gente não acolhe só uma pessoa, mas a gente acolhe a familia também (assistente social).

A psicóloga ressalta: esse serviço não é perfeito, está em processo, apesar de tantos anos que o hospital já é referência, nós ainda precisamos de uma rotina, de uma organização maior, de uma integração da equipe, de estrutura física [...].

Há, portanto, o reconhecimento por parte da equipe multiprofissional entrevistada sobre as deficiências do serviço, e o que poderia e deveria ser feito pra melhorar a atuação destes e consequentemente $o$ atendimento da usuária.

A enfermeira entende como um dos entraves para o atendimento adequado a questão do fluxo: pra mim, esse fluxo não é claro. Não está claro, e complementa:

Eu acho que funcionaria muito bem se tivesse um fluxo de entrada: essa paciente vai entrar como, ela vai passar por quem, ela vai pra onde, e que ela não ficasse indo de canto em canto, que tivesse um local pros profissionais irem acolher ela, ela já tão machucada, tão traumatizada, já em uma situação tão difícil pra ela ir procurando de lugar em lugar, acho que ela devia ficar num fluxo organizado, que devia ter um protocolo bem definido pra toda equipe... até porque a equipe tem que falar uma língua só (enfermeira).

A psicóloga, assim como a enfermeira e a assistente social, mencionou a importância de se ter capacitações para que os profissionais estejam mais preparados e sensibilizados para atuarem neste serviço, como vemos nas falas a seguir:

Eu acho que precisava de um espaço específico para atendê-la, precisaria capacitação, mais intensiva, constante, precisaria de estudos de casos com os profissionais, com todos, e precisaria que a comissão de violência fosse mais atuante, ne, fosse mais presente (psicóloga).

Já fiz um curso de atendimento a vitima de violência, e assim, mudou muito a minha visão depois do conhecimento que eu adquiri lá, sabe, mudou bastante (enfermeira).

Eu acho que deveria ter um grupo de estudo (assistente social). 
Como foi relatado pelos profissionais entrevistados, e pelo que foi observado por mim enquanto pesquisadora, de fato se trata de um serviço que não está perfeito, mas conta com uma equipe multiprofissional engajada e compromissada, além de interessada em atender da maneira mais adequada a usuária, apesar das limitações e entraves que ainda encontra e se depara no seu cotidiano profissional.

Somente assim, com a existência de profissionais compromissados eticamente com suas funções, esclarecidos e capacitados sobre os serviços aos quais estão envolvidos, é possível ultrapassar as limitações e dificuldades existentes para melhor atender aos usuários.

\section{Resultados do estudo: análise e discussão}

Com o objetivo de investigar como pensam e agem os profissionais de saúde que compõem a equipe multiprofissional responsável em atender mulheres em situação de violência sexual que desejam realizar o aborto legal no Hospital Distrital Gonzaga Mota Messejana, aplicamos 21 questionários a fim de coletar deles dados e questões referentes ao assunto em estudo para posterior análise e discussão.

Dos 21 questionários, seis foram respondidos por assistentes sociais, seis por psicólogos, cinco por médicos e quatro por enfermeiros, após consentirem participar depois de apresentada a pesquisa, e assinado o termo de consentimento livre e esclarecido.

\subsection{Aborto x Aborto legal x Aborto legal à mulher em situação de violência sexual}

Percebemos que há uma nítida diferenciação feita pelos profissionais em relação a estas três situações, ou seja, cada situação é vista de uma forma diferente pela grande maioria.

No que diz respeito ao aborto em si, enquanto que 13 se disseram contra, apenas quatro são a favor e quatro são indiferentes à questão. Já em relação ao aborto legal, 14 são a favor, ou seja, há o entendimento de que o aborto deve ser condenado e criminalizado, em contrapartida àquele previsto em lei, este passa a ser mais aceitável devido a esta legalidade antevista em nossa constituição.

Nos casos específicos de aborto legal após a mulher ter sofrido violência sexual, 16 se disseram a favor enquanto que apenas cinco são contra, ou seja, duas pessoas que eram contra o aborto legal em outros casos são a favor nestes casos de estupro que gerou uma gravidez indesejada. 


\subsection{0 serviço de atendimento à pessoa em situação de violência sexual e/ou aborto legal}

Dos 21 profissionais que responderam ao questionário, dos quais cinco são contra o aborto legal nos casos de violência sexual, apenas um é contra o serviço de atendimento à pessoa em situação de violência sexual.

Significa que o serviço que garante o acolhimento, a profilaxia, o atendimento social, psicológico e médico, ou seja, todos os cuidados que esta mulher necessita, é bem visto por eles, até mesmo por quatro deles que não concordam com o procedimento do aborto legal caso a usuária venha a desejar realizar.

\subsection{A equipe multiprofissional está capacitada para atender aos casos de violência sexual e de aborto legal?}

Dos 21 profissionais que responderam ao questionário, 20 afirmaram já ter atendido algum caso, e 16 acompanhou situação de aborto legal, no entanto, sem estarem capacitados para tal.

Dos 21, somente seis passaram por algum curso/seminário/oficina de capacitação sobre o atendimento à pessoa em situação de violência sexual ou aborto legal. Aqueles que afirmaram terem se capacitado de alguma forma sobre o tema, dois são assistente sociais, dois enfermeiros e dois médicos. Nenhum psicólogo, portanto, afirmou ter tido a oportunidade de se capacitar para melhor atender a usuária nestes casos.

\subsection{0 conhecimento dos profissionais sobre a legislação e a norma- tização referente ao atendimento a pessoa em situação de violência sexual e de aborto legal}

Para saber se os profissionais conhecem a lei, e, consequentemente realizam o atendimento à pessoa em situação de violência conforme o que é preconizado, garantindo assim os direitos inerentes a ela, perguntamos primeiramente quais são as três situações em que o aborto é permitido em nosso país, previsto em nosso Código Penal.

Neste caso, 16 profissionais respondem corretamente as três situações, enquanto que apenas cinco não responderam corretamente ou afirmaram não conhecer. Destes cinco, um é enfermeiro, dois são psicólogos e um é assistente social, já os cinco médicos responderam com louvor.

Nos casos de resposta incompleta referentes à essa questão, aqueles que responderam não esqueceram do aborto legal após estupro, assim como dos casos de anencefalia, mas esqueceram o aborto legal nos casos em que a mulher corre risco de morte, confundindo-se com má formação congênita ou quando ocorre microcefalia. A situação de violência sexual não poderia ser esquecida devido a ser a maior demanda que o hospital 
recebe, além de raros casos de anencefalia.

Outra questão perguntada é se o profissional conhece a lei que define as três possibilidades de ser feito o aborto, neste caso, o artigo 128 do Código Penal, e se conhece também a norma técnica lançada em 1999 e atualizada em 2012 pelo Ministério de Saúde, norma esta que regulamenta o serviço de atendimento a pessoa em situação de violência sexual nas unidades de saúde. Apenas 13 afirmaram conhecer, e oito disseram não conhecer, dos quais dois são médicos, um enfermeiro, três psicólogos e dois assistentes sociais.

$\mathrm{Na}$ questão seguinte, foi perguntado aos que afirmaram conhecer a lei e a norma técnica, se eles entendem se as mesmas são colocadas em prática no hospital que é campo deste estudo. Somente 13 responderam sobre isso, nove disseram que não totalmente, e apenas seis disseram que sim, totalmente, enquanto que os demais pularam a questão.

Podemos depreender destes dados que os profissionais conhecem, em sua maioria, as formas em que o aborto é permitido por lei - dos 21, 16 conhecem - mas não conhecem a lei, tampouco a norma técnica - dos 21, oito não conhecem. Por outro lado, mesmo sem conhecer a lei e a normatização que define como deve ser o serviço, a grande maioria - dos 13 profissionais que responderam, nove deles - afirmam que elas não são colocadas totalmente em prática no hospital em que atuam e que é o campo desta pesquisa.

Ainda sobre os conhecimentos que os profissionais possuem sobre o assunto em estudo, percebemos que poucos são os que conhecem a lei e a normatização, mas da mesma forma como eles, em sua grande maioria, conhecem as três formas do aborto ser realizado por lei, eles também sabem, de uma maneira geral, a documentação que deve ser obrigatoriamente apresentada pela usuária do serviço.

Sobre esta questão, uma observação que merece destaque é o fato de quatro pessoas terem respondido que deve ser exigido à mulher o boletim de ocorrência proveniente de uma delegacia, sendo destes quatro, dois médicos. Estes se mostraram enfáticos quanto a este fato.

Por outro lado, nenhum médico afirmou que a mulher precisa ser encaminhada do Instituto Médico Legal - IML, após ter feito exame de corpo delito para fins de comprovação da violência vivenciada, ao hospital para ser atendida pela equipe. Apenas dois profissionais fizeram esta afirmação, um assistente social e um psicólogo.

Referente ao encaminhamento do caso, através de relatório, ao Conselho Tutelar, por parte da equipe nas situações em que crianças e adolescentes são vítimas de violência sexual, o fato de 17 dos 21 profissionais terem respondido que é obrigatório ser feito pela equipe tal procedimento, demonstra a atenção que é dada quando se refere a este público específico.

\subsection{A atuação dos profissionais: como eles se veem}

Perguntamos aos profissionais que estavam respondendo o questionário, como eles percebem as práticas profissionais no serviço de atendimento a pessoa em situação de violência sexual existente no hospital campo desta pesquisa. Eles deveriam marcar as opções que eles entendiam como aquelas que, na percepção e experiência deles no seu 
cotidiano profissional, aconteciam e eram observados por eles.

Neste caso, a maioria declarou que os profissionais não gostam de atender a estas situações de violência - de 21, 15 não gostam -, assim como os profissionais não estão capacitados para tal - de 21, 15 não estão - e afirmaram ainda que eles fazem julgamentos às usuárias que são atendidas - de 21, um total de 12 fazem julgamentos.

Por outro lado, foi declarado também que os profissionais buscam atender conforme preconiza a lei - de 21, 12 agem desta forma - e estes atuam de maneira articulada com os demais que compõem a equipe - de 21, 15 atuam assim.

\section{Conclusão}

O assunto aborto legal, para alguns dos profissionais entrevistados, logo de imediato é acompanhado pela repulsa e pelo receio de falar sobre o assunto para "não se comprometer". Isto porque, de uma maneira geral, eles entendem que a usuária que chega para atendimento, independente da demanda que traz, deve ser acolhida e atendida conforme o que preconiza não só as normas técnicas mas também o seu código de ética enquanto profissional. No entanto, apresentam dificuldade porque esta é uma demanda diferenciada. E é diferenciada pelo fato de mexer com questões de foro intimo e pessoal, principalmente de caráter religioso e moral.

As explicações para o fato de alguns profissionais se recusarem a não só falar sobre o assunto mas também a atenderem a estes casos estão relacionadas a questões religiosas e de princípios morais, além do receio de ficarem conhecidos e estigmatizados como "profissional aborteiro". Parece ser muito mais glamoroso e compensatório ser conhecido como aquele que salva vidas, do que como aquele que "ajuda a matar e tira vidas inocentes". Por tudo isso, Soares (2003) afirma que identificar profissionais de saúde disponíveis a atuar neste serviço se trata de uma das maiores dificuldades para sua implantação.

No que se refere aos profissionais desta unidade de saúde, dos quatro entrevistados, todos eles atuam neste serviço, mas somente um se diz a favor do aborto. Da mesma forma, para aqueles que responderam ao questionário: a grande maioria é contra o aborto, sendo que uma parte considerada se diz a favor do aborto quando legal. Aqueles que são contra, atuam no serviço da mesma forma, pois entendem que devem fazer seu trabalho sem distinção de usuário e da demanda trazida por ele.

Vários são os autores que dialogam sobre a necessidade de se ter na unidade de saúde profissionais capacitados e qualificados para atuarem no serviço. Entende-se que, 
uma vez devidamente capacitados, a mulher vai ser adequadamente atendida conforme o que preconiza a lei e as normas técnicas.

No entanto, esta pesquisa possibilitou constatar que, no caso específico dos profissionais que atuam no Gonzaguinha de Messejana, estes, em sua grande maioria, sequer passaram por alguma capacitação, curso ou seminário sobre o tema. Assim, atuam conforme o que aprenderam, no cotidiano se suas ações no tocante a como deveriam proceder nestes casos.

A deficiência de capacitação e sensibilização sobre o assunto por parte da equipe reflete no conhecimento que ela possui sobre as questões referentes ao tema. Viu-se que a maioria dos profissionais conhece as formas em que o aborto é permitido por lei, no entanto desconhece a lei e a norma técnica. Mais grave ainda é perceber que a lei que regulamenta e define como deve funcionar o serviço da qual a unidade de saúde é referência é desconhecida. Ainda assim, a grande maioria afirma que ela é colocada totalmente em prática no campo da pesquisa.

Apesar de tais deficiências, foi possível perceber que eles buscam atuar de maneira ética e compatível com os cuidados exigidos pela usuária, uma vez que são coordenados por uma gestão que tem interesse em buscar formas de melhor atender a todos, bem como de garantir os direitos das usuárias previstos em lei.

Sob a ótica das políticas públicas percebe-se visibilidade por parte do governo, para que os órgãos atuem de maneira a garantir os direitos e cuidados necessários à pessoa que vivencia a violência sexual, bem como para que a sociedade perceba que se trata de uma questão que requer a devida atenção por parte de todos, assim como dos profissionais que atuam na área da saúde ao acolher este tipo de demanda.

Acredita-se que a pesquisa contribuirá para aprofundar o debate acerca da realidade das usuárias do serviço de atendimento a pessoas em situação de violência sexual, e mais especificamente de aborto legal, no campo da pesquisa. Deste modo, espera-se que o presente estudo constitua-se instrumento de consulta e de reflexão para os diversos profissionais que atuam com este público, na perspectiva de garantir um atendimento adequado e correto conforme o que preconiza a lei, e assim os direitos da usuária serem devidamente garantidos. 


\section{Referências Bibliográficas}

ALMEIDA, Suely Souza. Femicídio: algemas (in) visíveis do público-privado. Rio de Janeiro: REVINTER, 1998.

ANDALAFT NETO, Jorge. Violência sexual e interrupção da gestação prevista em lei: manual de orientação. São Paulo: Ponto, 2004.

BERGER, Sônia Maria Dantas. Violência sexual contra mulheres: entre a (in)visibilidade e a banalização. Rio de Janeiro, 2003. 184 p. Dissertação (Mestrado em Saúde Pública). Escola Nacional de Saúde Pública - Fundação Oswaldo Cruz.

BRASIL. Conselho Federal de Serviço Social. Parâmetros para atuação de assistentes sociais na política de saúde. Brasília, 2010.

Conselho Nacional de Saúde. Diretrizes e normas regulamentadoras sobre pesquisa envolvendo seres humanos. Resolução 196/96. Brasília, 1996.

Lei 8.069/90, de 13 de julho de 1990. Dispõe sobre o Estatuto da Criança e do Adolescente e dá outras providências. Diário Oficial da República Federativa do Brasil.

. Lei no 8.080, de 19 de setembro de 1990. Dispõe sobre as condições para a promoção, proteção e recuperação da saúde, a organização e o funcionamento dos serviços correspondentes e dá outras providências. Diário Oficial da República Federativa do Brasil.

Lei no 8.142, de 28 de dezembro de 1990.Dispõe sobre a participação da comunidade na gestão do Sistema Único de Saúde (SUS\} e sobre as transferências intergovernamentais de recursos financeiros na área da saúde e dá outras providências. Diário Oficial da Republica Federativa do Brasil. 
. Lei ํㅜ 12.845, de 1ำ de agosto de 2013. Dispõe sobre o atendimento obrigatório e integral de pessoas em situação de violência sexual. Diário Oficial da República Federativa do Brasil.

. Decreto no 7.958, de 13 de março de 2013. Estabelece diretrizes para o atendimento às vítimas de violência sexual pelos profissionais de segurança pública e da rede de atendimento do Sistema Único de Saúde. Diário Oficial da República Federativa do Brasil.

Portaria no 528 , de $1^{\circ}$ de abril de 2013. Define regras para habilitação e funcionamento dos Serviços de Atenção Integral às Pessoas em Situação de Violência Sexual no âmbito do Sistema Único de Saúde (SUS). Diário Oficial da República Federativa do Brasil.

Ministério da Saúde. Secretaria de Atenção à Saúde. Departamento de Ações Programáticas Estratégicas. Área Técnica de Saúde da Mulher. Prevenção e tratamento dos agravos resultantes da violência sexual contra mulheres e adolescentes: norma técnica. Brasília, Ministério da Saúde, 3. ed. 2012.

Ministério da Saúde. Secretaria de Ciência, Tecnologia e Insumos Estratégicos. Departamento de Ciência e Tecnologia. Aborto e saúde pública no Brasil: 20 anos. Brasília, Ministério da Saúde, 2009.

Ministério da Saúde. Secretaria Nacional de Assistência à Saúde. ABC do SUS Doutrinas e Princípios. Brasília, Ministério da Saúde, 1990.

Ministério da Saúde. Secretaria de Atenção à Saúde. Departamento de Ações Programáticas Estratégicas. Atenção Humanizada ao Abortamento: norma técnica. Brasília, Ministério de Saúde, 2005.

Ministério da Saúde. Secretaria de Atenção à Saúde. Política nacional de atenção integral à saúde da mulher: princípios e diretrizes. Brasília, Ministério de Saúde, 2004. 
Senado Federal. Lei no 11.340, de 07 de agosto de 2006. Lei Maria da Penha. Brasília, DF, 2007.

DIP, Andrea. Clandestinas. Agência de Reportagem e Jornalismo Investigativo. Publica. Direitos Humanos, 2013. Acesso em: http://apublica.org/2013/09/um-milhao-de-mulheres.

D’OLIVEIRA, Ana Flavia Pires Lucas e SCHRAIBER, Lilia Blima. Violência de Gênero como uma Questão de Saúde: a importância da formação de profissionais. Jornal da Redesaúde, São Paulo, nov. 1999.

DREZETT, Jefferson. Violência sexual contra a mulher e impacto sobre a saúde mental e reprodutiva. Revista de psicologia da UNESP, 2003.

FARIAS, Rejane Santos; CAVALCANTI, Ludmila Fontenele. Atuação diante das situações de aborto legal na perspectiva dos profissionais de saúde do Hospital Municipal Fernando Magalhães. Ciência e saúde coletiva, vol. 17, n. 7, p. 1755-1763, jul. 2012.

FAÚNDES, Aníbal et al. Violência sexual: procedimentos indicados e seus resultados no atendimento de urgência de mulheres vítimas de estupro. Rev. Bras. Ginecol. Obstet.,vol. 28, n. 2, p. 126-135, fev. 2006.

Conhecimento, opinião e conduta de ginecologistas e obstetras brasileiros sobre o aborto induzido. Rev. Bras. Ginecol. Obstet., vol. 26, n. 2,p. 89-96, mar. 2004.

LEMOS, Adriana e RUSSO, Jane Araújo. Profissionais de saúde e o aborto: o dito e o não dito em uma capacitação profissional em saúde. Interface, p.301-312, 2014.

LOUREIRO, David Câmara; VIEIRA, Elisabeth Meloni. Aborto: conhecimento e opinião de médicos dos serviços de emergência de Ribeirão Preto, São Paulo, Brasil, sobre aspectos éticos e legais. Cad. Saúde Pública, Rio de Janeiro, n. 20, p. 679-688, jun. 2004. 
MEDEIROS, Robinson Dias de et al. Opinião de estudantes dos cursos de Direito e Medicina da Universidade Federal do Rio Grande do Norte sobre o aborto no Brasil. Rev. Bras. Ginecol. Obstet., vol. 34, n. 1, p. 16-21, jan. 2012.

OLIVEIRA, Fátima. A violência contra a mulher é uma questão de saúde pública. Jornal da Redesaúde, São Paulo, nov. 1999.

ROCHA, W. et al. Percepção de profissionais da saúde sobre abortamento legal. Revista Bioética, Brasília, v. 23, n. 2, jul. 2015.

SOARES, Gilberta Santos. Profissionais de saúde frente ao aborto legal no Brasil: desafios, conflitos e significados. Cad. Saúde Pública, vol.19, n. 2, p. 399-406, 2003. 